\title{
Impact of DAFNE and subsequent CSII therapy on Glycaemic Control in Type-1 Diabetes Mellitus
}

\author{
Yunus S, Forde H, Browne S, Twamley H, Fanning E, Smith D. \\ Department of Endocrinology and Diabetes Mellitus, \\ Beaumont Hospital, Dublin, Ireland.
}

\section{Background}

- Dose Adjustment for Normal Eating (DAFNE) structured education programme is an effective tool in improving glycaemic control in patients with Type-1 diabetes while reducing the frequency of hypoglycemic episodes.

- DAFNE however, does not solve all glucose related problems and patients often request or are recommended continuous subcutaneous insulin infusion (CSII) therapy post DAFNE.

\section{Results}

- $56 \%$ patients were female.

- Mean Age was $40 \pm 9.4$ (mean $\pm S D$ ) years with a BMI of $26.6+4.5 \mathrm{~kg} / \mathrm{m}^{2}$

- Mean duration of Diabetes was 17.2 28.5 years.

- Duration since completion of DAFNE at the time of study was $5.8 \pm 2.2$ years.

- Duration of CSII therapy was 4.0 2.2 years.

- $\mathrm{HbA} 1 \mathrm{c}$ before DAFNE was 8.3 $\pm 1.2 \%(67.2 \pm 9.8$ $\mathrm{mmol} / \mathrm{mol})$ compared to $8.05 \pm 1.0 \%(64.5 \pm 11$ $\mathrm{mmol} / \mathrm{mol}) 12$ months post DAFNE - $p$ value $=0.31$. (Chart-1)

- The indication for commencement of CSII therapy was to improve overall glycemic control in $45 \%$ patients, impaired awareness of hypoglycaemia in $26 \%$ and patient preference, felt it would suit their lifestyle, in $23 \%$.

- HbA1c before commencement of CSII was $8.3 \% \pm 1.07(67.2 \pm 11.7 \mathrm{mmol} / \mathrm{mol})$ compared to $7.9 \% \pm 0.9(62.8 \pm 9.9 \mathrm{mmol} / \mathrm{mol})$ after 12 months of CSIl therapy $-p$ value $=0.04$. (Chart-2).

\section{Objective}

- Out of our 370 DAFNE graduates, 46 have subsequently gone on to CSII therapy.

- The aim of our audit was to examine glycaemic control of the 46 DAFNE graduates before and after they completed DAFNE \& then before and after starting CSII therapy and their reason for starting CSII therapy.

\section{Methods}

- The data was collected using the hospital's electronic database (CELLMA and PIPE) and by contacting the patients via phone for further details.

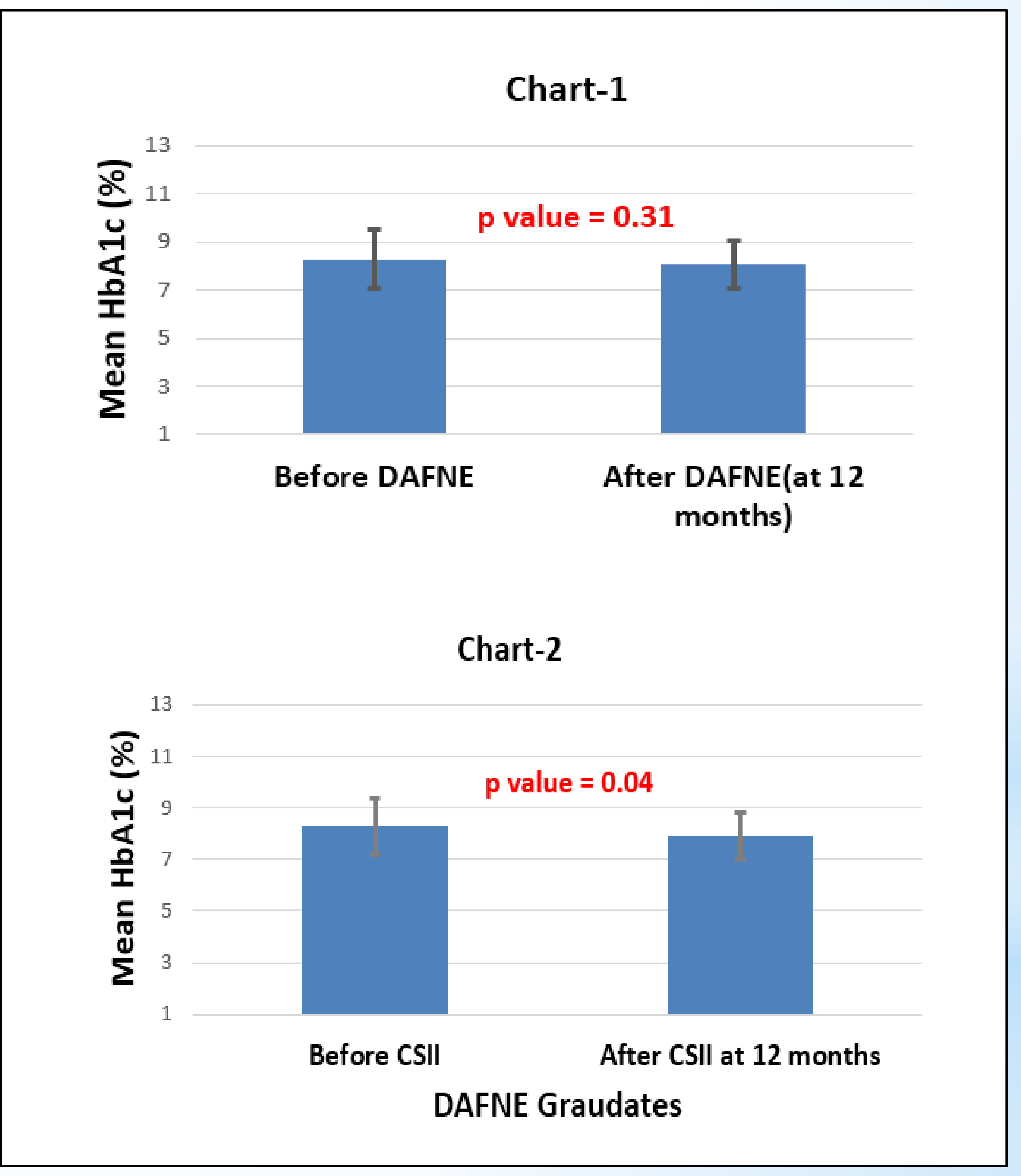

\section{Conclusion}

- DAFNE is an effective education programme for patients with Type-1 Diabetes but may not improve glycaemic control in all.

- Selected patients benefit from going on to CSII therapy post DAFNE and this can be associated with an improvement in their $\mathrm{HbA1c}$. 